Archives de sciences sociales des religions

160 | octobre-décembre 2012

Bulletin Bibliographique

\title{
Achilles Emilianides (éd.), Religious Freedom in the European Union
}

Leuven, Peeters, 2011, 418 p.

Jean-Louis Ormières

\section{CpenEdition}

Journals

Édition électronique

URL : http://journals.openedition.org/assr/23946

DOI : $10.4000 /$ assr.23946

ISSN : $1777-5825$

Éditeur

Éditions de l'EHESS

Édition imprimée

Date de publication : 30 décembre 2012

ISSN : 0335-5985

\section{Référence électronique}

Jean-Louis Ormières, «Achilles Emilianides (éd.), Religious Freedom in the European Union ", Archives de sciences sociales des religions [En ligne], 160 | octobre-décembre 2012, mis en ligne le 01 mars

2013, consulté le 21 septembre 2020. URL : http://journals.openedition.org/assr/23946 ; DOI : https:// doi.org/10.4000/assr.23946

Ce document a été généré automatiquement le 21 septembre 2020

(C) Archives de sciences sociales des religions 


\section{Achilles Emilianides (éd.), Religious Freedom in the European Union}

Leuven, Peeters, 2011, 418 p.

Jean-Louis Ormières

\section{RÉFÉRENCE}

Achilles Emilianides (éd.), Religious Freedom in the European Union, Leuven, Peeters, $2011,418 \mathrm{p}$. 
1 L'ouvrage rassemble les communications de la Conférence que le Consortium européen pour l'étude des relations Églises-État a organisée à Nicosie (Chypre) du 15 au 18 novembre 2007 et qui était consacrée à la question de la liberté religieuse dans les pays de l'Union européenne. Il s'agissait de présenter la législation de chacun des vingt-cinq pays sur cette question et la manière dont l'article 9 de la Convention européenne (droit à la liberté de pensée, de conscience et de religion) est interprété par les tribunaux de chacun de ces pays et les aménagements apportés par les législations nationales pour se conformer au respect de l'article. La jurisprudence, notamment l'affaire Kokkinakis contre la Grèce (1993), la première procédure concernant la liberté de religion portée

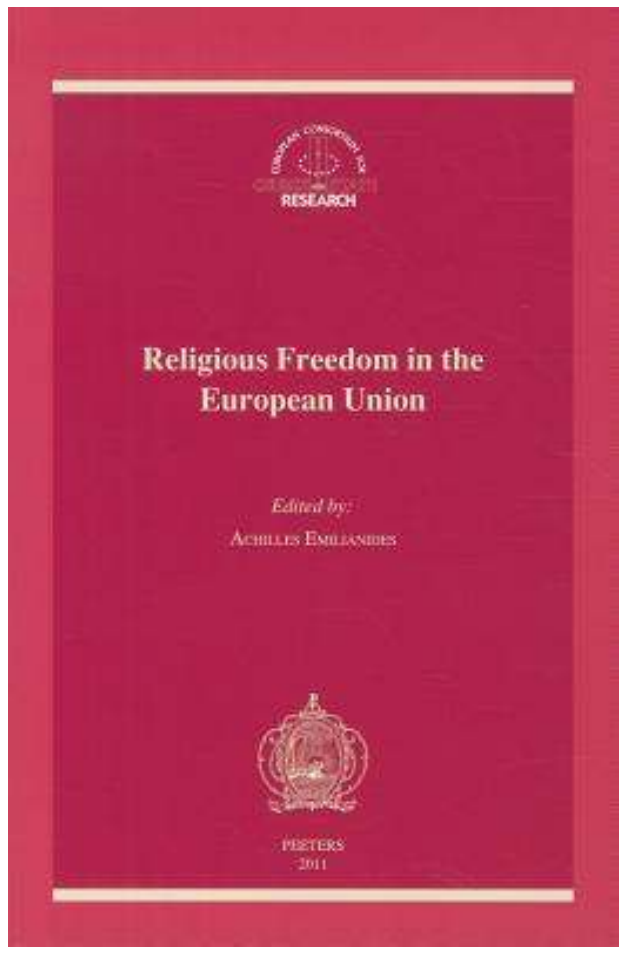
devant la Cour européenne, a permis de préciser la portée de cet article soulignant notamment qu'il implique non seulement la liberté d'adhérer ou non à une religion, mais aussi celle de la pratiquer ou de ne pas la pratiquer, c'est-à-dire de la manifester ou non. Arrêté par les autorités pour prosélytisme abusif, le couple Kokkinakis avait vu, dans un premier temps, sa requête rejetée par la Cour européenne, celle-ci ayant fait la distinction entre prosélytisme «purement évangélique» faisant partie de la liberté de manifester et prosélytisme « abusif ». Mais, par la suite, en 1998, la Cour a été contrainte d'apporter une nouvelle distinction entre "prosélytisme de mauvais aloi » (condamnable) et « prosélytisme de bon aloi ».

2 La possibilité pour chacun des nationaux des États membres d'avoir recours à la Cour européenne des Droits de l'Homme pour faire respecter l'article 9 en dépit du caractère multiforme de l'interprétation possible de cet article induit de fait une harmonisation de la législation en matière de liberté religieuse. Comme le rappelle Christine Pauti dans sa communication sur la France, il faut néanmoins souligner que la Cour Européenne confère également une certaine marge d'appréciation aux États en cette matière. Cette " autonomie » va-t-elle demeurer ou plutôt s'affaiblir progressivement comme semble le penser Malcolm D. Evans dans le rapport de synthèse en conclusion de l'ouvrage ? Faisant remarquer que ce sont les hautes juridictions des États en voie de transition politique de l'Europe centrale et orientale qui ont le plus recours à l'article 9, il y voit le signe d'un « consensus pan européen » à venir. Le cas de la Pologne, où les recours à la Convention européenne et les entraves aux principes de liberté religieuse sont rares, paraît aller dans ce sens. Il reste que, plus globalement, outre le fait que les juridictions propres à chaque état sont elles-mêmes pourvues de moyens permettant de faire respecter la liberté de religion et de pensée, les citoyens de la Communauté européenne peuvent invoquer ou s'appuyer sur d'autres articles que l'article 9 (en particulier l'article 10 sur la liberté d'expression ou l'article 1 sur l'interdiction de 
discrimination) pour poursuivre devant la Cour européenne toute atteinte à cette liberté ou au droit de pratiquer et de manifester son appartenance religieuse.

3 La création de la Cour européenne ne peut, aux yeux des juristes qui y travaillent et des auteurs de cet ouvrage, que contribuer à l'amélioration de la situation des croyants dans chacun des pays signataires de la Convention. Les nombreux recours témoignent du bienfait de cette institution. On regrettera néanmoins l'absence de données chiffrées permettant d'évaluer ce constat optimiste. D'autant que les contraintes qui pèsent sur les juridictions nationales sont souvent sans effet réel. Ainsi, pour ne prendre qu'un exemple - celui de la Grèce - en dépit de la condamnation par la Cour européenne des droits de l'homme du statut privilégié de l'Église orthodoxe grecque (1996), les autorités de ce pays n'ont pris aucune mesure assurant un traitement plus égal aux communautés religieuses. 